\title{
Audit System Informasi Absensi Pada PT Multi Engineering Perkasa Dengan Metode Framework Cobit
}

\author{
Tukino \\ Program Studi Sistem Informasi Fakultas Teknik dan Komputer Universitas Putera Batam \\ Jl. R. Soeprapto Muka Kuning, Kibing, Kec. Batu Aji, Kota Batam, Kepulauan Riau 29434, \\ telp. $+62857-7571-0743$ \\ e-mail: tukino@puterabatam.ac.id
}

\begin{abstract}
Abstrak
Perusahaan ini telah memiliki system informasi absensi untuk mencatat kehadiran karyawannya menggunakan mesin sidik jari. Tujuan dari penelitian ini adalah untuk mengukur tingkat kematangan untuk mencari permasalahan yangmuncul dalam proses system informasi absensi untuk memberikan rekomendasi kepada perusahaan untuk memperbaiki manajemen TI yangada. Selama penelitian, penulis menggunakan kerangka kerja COBIT 4.1, dengan fokus pada domain ME, yangterdiri dari subdivisi ME1, ME2, ME3 ME4. Hasil Survei Frekuensi Maturitas System Informasi menggunakan proses-proses yangterdapat pada subsektor ME1 yangmemiliki nilai pembulatan sampai dengan 3, subsektor ME2 yangmemiliki nilai pembulatan sampai dengan 3, ME3. subdomain dengan nilai 3 dibulatkan subdomain ME4 dengan nilai 3 dibulatkan. Pada kematangan TI Level 3, perusahaan harus mengevaluasi setiap proses atau prosedur system; solusi perbaikan harus dilakukan secara konsisten sampai system dalam kondisi optimal. Hasil dari penelitian ini adalah tingkat kematangan TI saat ini (sebagaimana adanya), dengan rata-rata peringkat 3 (proses yangdisetujui), hanya 2 (proses yangdikelola) kematangan domain pemantauan. Deliver, Service Support domain, kemudian Friends hasil kematangan teknologi informasi untuk memberikan saran perbaikan perusahaan. Perusahaan menerima benchmark kematangan TI berdasarkan COBIT 4.1, serta rekomendasi yangdapat diikuti dalam perusahaan untuk perbaikan di masa mendatang.
\end{abstract}

Kata kunci Audit System Informasi, COBIT 4.1, Domain ME, Tingkat Kematangan

\begin{abstract}
The company already has an attendance information system to record the attendance of its employees through the fingerprint machine. The purpose of this study is to measure the level of maturity to look for problems that arise in the process of attendance information system to make recommendations to companies to improve existing IT management. The authors used the COBIT 4.1 framework in their research, focusing on the ME domain, which consists of ME1, ME2, ME3 ME4 subsectors. The results of the study related to the level of maturity of the attendance information system using the processes contained in sub-sector ME1, which has a value of 3 rounded, sub-sector ME2, which has a value of 3 rounded. , ME3 subdomain, which has a value of 3 rounded ME4 subdomain, which has a value of 3 rounded. solutions must be implemented consistently until the system is in optimal condition. The results of this study are the current level of IT maturity (as it stands), with an average of 3 (approved process) rating,

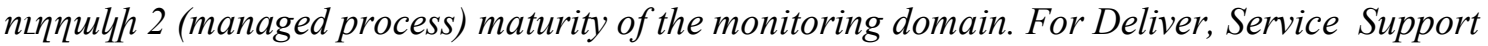
domain., then, as a result of the maturity of information technologies, the company is given suggestions for improvement. The company receives an IT maturity benchmark based on COBIT 4.1, as well as recommendations that may be followed within the company for future improvements.
\end{abstract}

Keywords Systems Information Audit, COBIT 4.1, ME Domain, Maturity Level.

\section{Pendahuluan}

Teknologi informasi (TI) adalah sesuatu yangsangat penting saat ini bagi hampir semua organisasi, perusahaan dan institusi untuk membantu meningkatkan efisiensi dan efektivitas 
proses eksekusi. Penggunaan TI saat ini tidak hanya digunakan di organisasi swasta, tetapi juga di organisasi/lembaga pemerintah. Upaya pengenalan TI di lembaga e-government (egovernment) ditujukan untuk meningkatkan kualitas pelayanan publik agar lebih efektif, efisien menjangkau berbagai segmen masyarakat.[1]. Penggunaan TI di institusi memiliki risiko kegagalan yangcukup tinggi[2]. Namun, penggunaan TI juga memungkinkan institusi mengalami transformasi dan meningkatkan produktivitas operasi mereka saat ini.[3]. Pencapaian tujuan tersebut memerlukan system manajemen system teknologi informasi yangberkualitas untuk memaknai keberadaan TI guna mencapai tujuan organisasi/lembaga.[1].

Dengan perkembangan teknologi yangsemakin maju membawa dunia bisnis pada persaingan yangefektif dan efisien [1]. PT Sinar Pratama Agung merupakan salah satu perusahaan yangmenyewakan alat berat crane.[2]. Berkat teknologi, perusahaan ini memperkenalkan system informasi untuk mendukung proses bisnisnya, misalnya penggunaan system informasi absensi di perusahaan. Perlu dilakukan evaluasi terhadap system prosesprosesnya, yangbertujuan untuk memastikan bahwa system informasi absensi yangdigunakan perusahaan menjamin kenyamanan proses bisnis perusahaan Meningkatkan pengelolaan TI yangbaik sesuai dengan perusahaan misi. Audit dapat dilakukan, yangmungkin bertanggung jawab untuk menilai efektivitas manajemen TI sesuai dengan prosedur yangditerapkan pada perusahaan.

Teknologi informasi adalah bagian yang sangat penting dari situs web atau organisasi Anda. Dengan bantuan teknologi informasi, organisasi atau lembaga menghabiskan sedikit sumber daya investasi, yang dapat digunakan dalam bentuk sumber daya keuangan, waktu sumber daya lainnya: Analysis kinerja TI TI berfungsi untuk mendukung organisasi TI raksasa sumber daya secara efisien, memastikan organisasi aset, menjaga integritas dan keamanan data organisasi, serta mancapai tujuan organisasi yang efektif sesuai standar COBIT. Saat ini, kerangka kerja sedang dikembangkan untuk mendukung pengelolaan organisasi atau lembaga Anda, dan Anda akan menemukan COBIT 4 [2].

Inti dari penelitian ini adalah bahwa PT Multi Engineering Perkasa, salah satu perusahaan yangbergerak di bidang penyewaan alat berat crane di Batam, telah lama berinvestasi dalam system informasi kehadiran. Hal ini dilakukan untuk menjamin kenyamanan karyawan, untuk menghindari kegiatan penipuan atau penipuan data karena ketidakhadiran karyawan atau karyawan. Untuk mendukung system informasi absensi terdapat mesin sidik jari yangterhubung dengan system sehingga karyawan ingin melakukan pencatatan kehadiran.

Dari sisi system informasi khususnya absensi, PT Multi Engineering Perkasa salah satu perusahaan yangmenyewakan alat berat crane di Batam sudah lama berinvestasi pada system informasi terkait absensi. Hal ini dilakukan untuk menjamin kenyamanan karyawan, untuk menghindari kegiatan penipuan atau penipuan data karena ketidakhadiran karyawan atau karyawan. Untuk mendukung system informasi absensi terdapat mesin sidik jari yangterhubung dengan system sehingga karyawan ingin melakukan pencatatan kehadiran. Demikian penjelasan mengenai proses yangdilakukan oleh karyawan PT Multi Engineering Perkasa pada saat melakukan registrasi menggunakan mesin sidik jari yaitu. Tahap atau langkah pertama dimulai ketika karyawan PT Multi Engineering Perkasa datang langsung ke kantor sesuai jadwal perusahaan pada jam kerja. Karyawan kemudian dapat mulai mendaftarkan kehadiran dengan menempatkan sidik jari mereka pada mesin sidik jari PT Multi Engineering Perkasa. Mesin sidik jari dapat mengidentifikasi seorang pegawai jika sidik jari pegawai tersebut sebelumnya telah terdaftar pada mesin sidik jari. Karyawan kemudian dapat mulai mendaftarkan kehadiran dengan menempatkan sidik jari mereka pada mesin sidik jari PT Multi Engineering Perkasa. Mesin sidik jari dapat mengidentifikasi seorang pegawai jika sidik jari pegawai tersebut sebelumnya telah terdaftar pada mesin sidik jari. Karyawan kemudian dapat mulai mendaftarkan kehadiran dengan menempatkan sidik jari mereka pada mesin sidik jari PT Multi Engineering Perkasa. Mesin sidik jari dapat mengidentifikasi karyawan, Jika sebelumnya sidik jari karyawan terdaftar di mesin sidik jari, karyawan dapat memulai pendaftaran dengan menempelkan sidik jarinya pada mesin sidik jari PT Multi Engineering Perkasa. Sebuah mesin sidik jari dapat mengidentifikasi seorang karyawan jika sidik jari karyawan tersebut sebelumnya telah terdaftar 
pada mesin sidik jari tersebut. Karyawan dapat memulai pendaftaran dengan menempelkan sidik jarinya pada mesin sidik jari PT Multi Engineering Perkasa. Sebuah mesin sidik jari dapat mengidentifikasi seorang karyawan jika sidik jari karyawan tersebut sebelumnya sudah terdaftar pada mesin sidik jari Jika sebelumnya sidik jari karyawan tersebut telah terdaftar pada mesin sidik jari, maka karyawan dapat mulai melakukan pendaftaran dengan menempatkan sidik jarinya pada mesin sidik jari PT Multi Engineering Perkasa. Mesin sidik jari dapat mengidentifikasi seorang karyawan jika sidik jari sudah terdaftar sebelumnya di mesin sidik jari Jika sebelumnya sidik jari karyawan sudah terdaftar di mesin sidik jari, maka karyawan dapat mulai melakukan pendaftaran dengan menempelkan sidik jarinya di mesin sidik jari PT Multi Engineering Perkasa. Mesin sidik jari dapat mengidentifikasi seorang karyawan jika sidik jari karyawan tersebut sebelumnya telah terdaftar di mesin sidik jari

Pada umumnya para pelaku usaha menggunakan teknologi informasi untuk mendukung setiap kegiatan usaha di dalam perusahaan agar dapat berjalan dengan optimal. Ada beberapa jenis teknologi yangbiasa digunakan oleh perusahaan terutama untuk membantu bagian manajemen sumber daya manusia dalam pengelolaan informasi di perusahaan salah satunya dengan menggunakan teknologi system informasi absensi. Absensi merupakan bagian penting dari perusahaan, sebagai informasi terkait kehadiran karyawan kemanfaatan waktu sesuai dengan aturan perusahaan standar operasional dapat diketahui dari saat kehadiran. Jadi pada prinsipnya system absensi dapat membantu manajemen untuk memantau kondisi karyawan dalam melaksanakan pekerjaannya, agar perusahaan dapat memaksimalkan kinerja karyawan mencapai tujuan yangmenjadi tujuan perusahaan. System Informasi Absensi adalah suatu system yangberoperasi untuk mencatat atau mencatat setiap pegawai atau daftar partisipasi pegawai. System informasi absensi biasanya menggunakan alat tambahan berupa mesin sidik jari, karena berfungsi untuk mempermudah proses absensi yangdilakukan oleh perusahaan atau karyawannya. System Informasi Absensi adalah suatu system yangberoperasi untuk mencatat atau mencatat setiap pegawai atau daftar partisipasi pegawai. System informasi absensi biasanya menggunakan alat tambahan berupa mesin sidik jari, karena berfungsi untuk mempermudah proses absensi yangdilakukan oleh perusahaan atau karyawannya. System Informasi Absensi adalah suatu system yangberoperasi untuk mencatat atau mencatat setiap pegawai atau daftar partisipasi pegawai. System informasi absensi biasanya menggunakan alat tambahan berupa mesin sidik jari, karena berfungsi untuk mempermudah proses absensi yangdilakukan oleh perusahaan atau karyawannya.[3].

Terdapat informasi bahwa tingkat kesiapan TI dapat diketahui melalui audit system informasi, karena hasil audit tersebut memuat penilaian efektivitas setiap proses pengelolaan TI. tercantum dalam prosedur yangdisetujui oleh perusahaan.[4]. Audit system informasi membantu manajemen perusahaan untuk melakukan audit risiko, sehingga meningkatkan keamanan system organisasi dengan menilai proses system organisasi kontrol atas baseline. Audit direncanakan dirancang untuk memberikan penilaian independen untuk memberikan penilaian. Audit juga dapat memberikan analysis kesenjangan pengendalian internal atau efektivitas operasional. Keberhasilan suatu perusahaan saat ini tergantung pada kondisi pengelolaan TI, karena keterpaduan penerapan TI antara strategi bisnis perusahaan dapat dicapai jika terdapat kondisi pengelolaan teknologi yangbaik.[5].

Disini peneliti menggunakan COBIT sebagai penelitian berdasarkan penelitian sebelumnya. Penilaian Manajemen TI di Pegadaian Kanwil X Bandung menggunakan Framework Cobit 4.1 Survei tata kelola TI ini menggunakan framework COBIT 4.1[6]. Alasan pemilihan kerangka kerja ini adalah karena COBIT 4.1 sepenuhnya mencakup semua aspek perusahaan. Industri pengolahan membahas strategi dan pengendalian agar penggunaan manajemen TI sejalan dengan tujuan bisnis. Audit Sistem Informasi (TI)/IT adalah tahap pengumpulan bukti untuk menilai apakah suatu sistem informasi dapat melindungi aset perusahaan; teknologi informasi yang ada telah menjaga integritas data sehingga keduanya dapat secara efektif mencapai tujuan bisnis [7]. Pada prinsipnya, audit system informasi harus dilakukan sebagai audit terpisah dan bukan sebagai bagian dari audit laporan keuangan untuk menentukan tingkat kematangan atau kemauan entitas untuk mengelola manajemen TI 
(teknologi informasi). Tingkat kematangan dapat dilihat pada tingkat pengelolaan informasi, tingkat kepedulian seluruh pemangku kepentingan, posisi saat ini, arah yangdiinginkan di masa depan. Sehingga perencanaan IT tidak harus dilakukan sembarangan[8].

Manajemen TI Manajemen TI memastikan bahwa perusahaan mencapai tujuan dan sasarannya dengan menilai pemangku kepentingan, kebutuhan, keadaan, serta pilihan. Memprioritaskan, serta pengambilan keputusan, kontrol kinerja, loyalitas arah menuju tujuan [9]. Manajemen TI juga dikelola oleh seluruh pemangku kepentingan yangterkait dengan organisasi. Transparansi setiap pemangku kepentingan diperlukan untuk peran, pengaruh tanggung jawab masing-masing pemangku kepentingan[10]. Agar layanan TI dapat berfungsi seperti yangdiinginkan, pengelolaan TI perlu didukung. Dalam implementasinya, agar pengelolaan TI dapat berjalan efektif, organisasi harus mengukur tingkat pengelolaan yangdimiliki saat ini dan mengidentifikasi perkembangan yangdapat dilakukan. Ini terjadi pada semua tahap yangperlu dikelola di sektor TI dalam proses manajemen itu sendiri.[11].

COBIT adalah salah satu alat atau pedoman untuk membangun manajemen TI [12]. COBIT digunakan untuk manajemen TI sebagai risiko bisnis, kebutuhan dukungan TI untuk tujuan TI Dukungan untuk beberapa masalah teknis terkait TI.[13]. Kerangka kerja COBIT digunakan untuk mengontrol pemetaan komunikasi proses pengembangan proyek[14].

Salah satu alat untuk mengukur kinerja suatu system TI adalah model tingkat kematangan. Berfungsi untuk mereview setiap proses IT menggunakan metode appraisal sehingga perusahaan dapat menentukan dimana tingkat kematangan system yangada dapat terus menaikkan level ke level tertinggi.[15].

Melalui penelitian ini, mengutip kerangka COBIT 4.1, domain fase PO7 (Domain Plan and Organize), fase DS (Domain Delivery and Support) fase DS1 DS10 fase ME (Domain Monitor and Evaluate) fase ME1 ME4. [15].

Proses pengelolaan ini dapat menghasilkan hasil rekomendasi yangdapat digunakan di Kantor Pengadaan Kota Batam sebagai panduan untuk meningkatkan tata kelola perusahaan pengelolaan TI yangmenitikberatkan pada risiko kinerja pengelolaan system TI agar dapat lebih baik lagi. untuk mendukung tujuan bisnis organisasi. Agar pengelolaan TI dapat efektif di suatu perusahaan, perusahaan harus dapat menilai sejauh mana pengelolaan TI saat ini mengidentifikasi perbaikan yangdapat dilakukan. Terkait dengan pengelolaan TI, diperlukan mekanisme audit pengelolaan TI. Secara umum, Kerangka Manajemen TI Kontrol yangdiperlukan untuk mencapai hal ini disediakan di bawah kerangka kerja COBIT. COBIT dapat digunakan sebagai alat yangkomprehensif untuk membangun manajemen TI di sebuah perusahaan.

Model maturitas digunakan sebagai alat untuk penilaian diri dan pengukuran manajemen teknologi informasi yang lebih efektif. Model kematangan manajemen proses TI didasarkan pada metode evaluasi perusahaan atau organisasi sehingga dapat mengevaluasi dirinya sendiri dari level 0 (tidak ada) hingga 5 level (dioptimalkan).

Tabel 1. Model maturitas

\begin{tabular}{cl}
\hline Tingkat & \multicolumn{1}{c}{ Kriteria kedewasaan } \\
\hline $\mathbf{0}$ & $\begin{array}{l}\text { Mengenali tidak adanya proses yangtidak terdeteksi. Perusahaan bahkan } \\
\text { tidak tahu bahwa ada masalah yangperlu dipecahkan. }\end{array}$ \\
Tidak ada & Ada bukti bahwa perusahaan menyadari masalah yangperlu ditangani. \\
$\mathbf{1}$ & Namun, tidak ada proses standar, tetapi digunakan pendekatan sementara \\
Awal / & $\begin{array}{l}\text { yangcenderung individual atau individual. Secara umum, pendekatan } \\
\text { manajemen proses tidak terorganisir. }\end{array}$ \\
& $\begin{array}{l}\text { Proses berubah menjadi tahap dimana prosedur yang sama dilakukan oleh } \\
\text { pihak yang berbeda untuk pekerjaan yang sama. Tidak ada pelatihan formal }\end{array}$ \\
$\mathbf{2}$ & atau komunikasi tentang prosedur standar. Tanggung jawab diserahkan \\
kepplikat Tapa individu. Ada tingkat kepercayaan yang tinggi dalam pengetahuan \\
Intuitif & pribadi, sehingga kemungkinan kesalahan sangat tinggi. \\
\hline $\mathbf{3}$ & $\begin{array}{l}\text { Prosedur distandarisasi, didokumentasikan, dan kemudian dikomunikasikan } \\
\text { melalui pelatihan. Kemudian diinstruksikan bahwa proses ini harus diikuti. }\end{array}$ \\
\hline ditentukan & https://doi.org/10.31849/digitalzone.v12il.6676
\end{tabular}




\begin{tabular}{cl}
\hline Tingkat & \multicolumn{1}{c}{ Kriteria kedewasaan } \\
\hline & $\begin{array}{l}\text { Namun, penyimpangan tidak dapat dideteksi. Prosesnya sendiri tidak } \\
\text { lengkap, tetapi ini adalah praktik saat ini. }\end{array}$ \\
$\mathbf{4}$ & $\begin{array}{l}\text { Monitor kontrol mengukur kepatuhan dengan prosedur operasi jika proses } \\
\text { tidak dapat dilakukan secara efisien. Proses terus meningkat, praktik yang }\end{array}$ \\
dikontrol & baik dipastikan. Otomatisasi perangkat digunakan dalam batas-batas \\
Dapat diukur & tertentu. \\
& $\begin{array}{l}\text { Proses tersebut dipilih berdasarkan pengalaman yang baik, berdasarkan } \\
\text { hasil continuous improvement dan maturation modeling dengan perusahaan }\end{array}$ \\
Dioptimalkan & lain. Teknologi informasi digunakan sebagai alat terintegrasi untuk \\
& otomatisasi alur kerja - kualitas alat efisiensi adaptasi cepat perusahaan. \\
\hline
\end{tabular}

Sumber[15]

Beberapa cara umum untuk menilai kedewasaan meliputi [15]

a) Pendekatan multidisiplin untuk sekelompok orang yangmendiskusikan dan menyepakati tingkat kedewasaan saat ini.

b) Buatlah uraian tentang syarat-syarat pembayaran kembali menjadi beberapa pernyataan agar pihak manajemen dapat memastikan tingkat persetujuannya.

c) Penggunaan properti matriks seperti yangdidokumentasikan dalam COBIT

d) Pedoman Manajemen Tetapkan nilai untuk setiap fitur dari setiap proses.

Penelitian sebelumnya yangdigunakan dalam penelitian ini adalah [16], dimana penelitian ini mengukur tingkat keterampilan manajemen di PT. PDA Net menggunakan COBIT 4.1. Penelitian sebelumnya lainnya[17] Selama studi ini, penilaian tingkat kapasitas dilakukan di BAI07 COBIT 4.1 pada system pendidikan jarak jauh STIK-PTIK. Merujuk pada penelitianpenelitian sebelumnya, maka penulis tertarik untuk melakukan penelitian tentang "Audit System Informasi Absensi Pada PT Multi Engineering Perkasa Menggunakan Metode Cobit Framework". Ada kesamaan antara penelitian sebelumnya saat ini menggunakan COBIT 4.1. Perbedaan survey sebelumnya dan sekarang adalah untuk menganalisa apakah IT/TI yangdigunakan di PT Multi Engineering Perkasa Kota Batam menerima hasil penelitian ini, tingkat kematangan IT saat ini (as stand), rata-rata pada nilai kematangan. 3 (Proses yangdibuat) evaluasi domain, koreksi.

\section{Metode penelitian}

Dalam penelitian ini, penulis menggunakan metode kualitatif. Subyek metode kualitatif adalah individu (individu). Tidak semua langkah dan langkah yangterdapat dalam pedoman selama audit level atau tahap digunakan untuk penelitian ini untuk mengurangi pengulangan kegiatan yangpenulis mematuhi aturan umum yangditetapkan. COBIT adalah kerangka kerja yangdigunakan untuk audit system informasi. Kemampuan memahami ruang lingkup COBIT untuk mempermudah pembahasan manajemen system informasi, yangakan dipaparkan secara singkat. Tahapan audit system informasi adalah

a) Tentukan ruang lingkup tugas audit TI / TI

Pada tahap ini, tentukan area atau lingkungan yangingin Anda periksa yangdicakup oleh system dengan cara khusus oleh perusahaan yangterlibat dalam penelitian. Tujuan audit TI/TI harus ditafsirkan sebagai tujuan yangterperinci, karena keputusannya dipengaruhi oleh langkah-langkah yangakan dilakukan oleh audit TI/TI.

b) Mengumpulkan bukti

Bukti yangdikumpulkan berupa informasi untuk menentukan kesesuaian data yangdiaudit dengan standar serta tujuan audit. Bukti diperoleh melalui observasi melalui wawancara langsung dengan staf atau pemangku kepentingan.

c) Ketekunan yangtepat

Uji kepatuhan dilakukan dengan memeriksa kesesuaian tahapan teknologi informasi dengan system operasi. Hasil pengujian yangmemadai merupakan hasil yangdiperoleh, yangnantinya akan digunakan sebagai bahan penyusunan rekomendasi laporan audit.

d) Penentuan tingkat maturitas (tingkat maturitas system) 
Tingkat kematangan system didefinisikan untuk menggambarkan pengukuran apakah perusahaan telah memenuhi standar manajemen TI yangbaik. Tingkat maturitas memiliki tingkatan-tingkatan yangdikelompokkan dari nol (0) sampai dengan lima (5) pada setiap tingkatannya, yangberisi berbagai pernyataan yangdijadikan acuan untuk mengukur jarak antar proses di perusahaan.

e) Menentukan hasil audit system TI/TI

Hasil audit yangdiperoleh dari penilaian hasil audit akan diubah menjadi opini dan kemudian opini yangdikembangkan akan digunakan sebagai rekomendasi audit. Keputusan audit dibuat dengan meninjau hasil yangdiperoleh.

f) Kompilasi hasil audit SI / TI rekomendasi

Laporan audit berisi uraian kesimpulan pernyataan konstruktif terkait perbaikan system manajemen. Pengumuman konstruktif berupa rekomendasi atau rekomendasi dari hasil audit, yangdilakukan dengan tujuan untuk memperbaiki proses system yangsedang berjalan di perusahaan.

Dari penjelasan di atas, proyek penelitian audit dapat digambarkan seperti yangditunjukkan pada Gambar 1 di bawah ini.

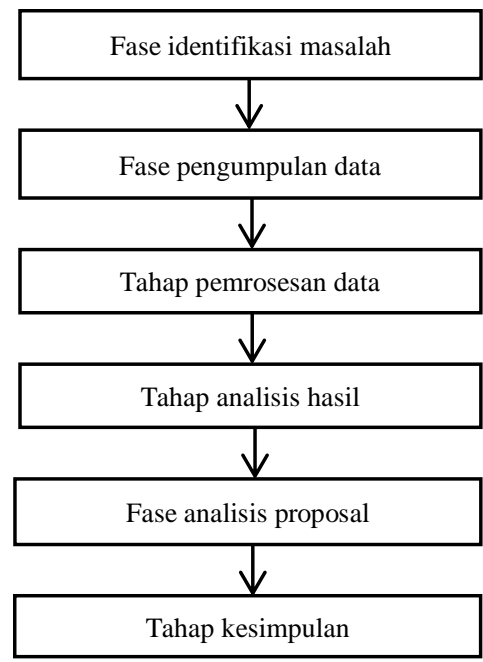

Sumber Data survei, 2021

Gambar 1. Desain penelitian

Penjelasan proses penelitian pada gambar di atas adalah sebagai berikut.

a) Awal

Identifikasi masalah penelitian, tentukan batasan masalah, serta studi pendahuluan, termasuk literatur, objek penelitian.

b) Fase pengumpulan data

Ada kegiatan pengumpulan data penelitian, antara lain survei, wawancara dengan staf PT Multi Engineering Perkasa, dan pengelolaan kuesioner yangdisesuaikan dengan COBIT 4.1, dengan fokus pada domain ME.

c) Tahap pemrosesan data

Pengolahan data dengan menghitung kesenjangan tingkat kematangan menggunakan framework COBIT. 4.1.

d) Tahap analysis hasil

Pada tahap ini terdapat penjelasan hasil perhitungan tingkat kematangan pembiaran.

e) Fase analysis proposal

Memberikan rekomendasi sesuai hasil pada tingkat kematangan.

f) Tahap kesimpulan

Penjelasan hasil penelitian secara keseluruhan, termasuk hasil penelitian Rekomendasi mengenai penghilangan tingkat kematangan pada PT Multi Engineering Perkasa. 


\subsection{Metode analysis}

a) Analysis tingkat kapasitas

Analysis Tingkat Kemampuan dilakukan berdasarkan hasil Kuesioner Manajemen System Informasi Lalu Lintas menggunakan mesin sidik jari domain ME yangterdiri dari subdivisi ME1, ME2, ME3 ME4.

b) Analysis kesenjangan

Kesenjangan ditentukan oleh analysis hasil kuesioner yangmengarah pada perbedaan tingkat kapasitas, dari hasil tersebut dimungkinkan untuk menganalisis kesenjangan yangterdapat dalam hasil penelitian. Analysis kegagalan digunakan untuk membedakan antara maturitas saat ini mencapai maturitas, analysis gap level bertujuan untuk mencari solusi berupa rekomendasi perbaikan yangakan dilaksanakan oleh departemen manajemen, yangdirancang untuk mencapai tingkat maturitas yangdiinginkan. Dengan demikian, rumus untuk menghitung analysis gap adalah sebagai berikut

Kesenjangan $=\mathrm{X}-\mathrm{Y}$ :

Informasi:

$\mathrm{X}=$ Tingkat kedewasaan yang ingin Anda capai

$\mathrm{Y}=$ Tingkat kematangan saat ini

Persamaan 2.1 Analisis kesenjangan

Sumber[15]

\section{Hasil dan Pembahasan}

Pada bagian ini akan dibahas mengenai System Informasi Kerangka Kerja COBIT PT Multi Engineering Perkasa. Analysis lingkungan TI di sini, mulai dari staf, peralatan, keamanan fisik, dan peraturan.

\subsection{Pemetaan kuesioner dengan matriks RACI}

Dengan demikian, rincian isi kuesioner menurut subsektor yangberasal dari domain ME setelah disesuaikan dengan matriks RACI adalah sebagai berikut

a) subsektor ME1

ME1.1 - Pendekatan Pemantauan (R)

ME1.2 - Definisi Data Pemantauan Pengumpulan (C)

ME1.3 - Metode Pemantauan (R)

ME1.4 - Evaluasi Kinerja (I)

ME1.5 - Rekomendasi Laporan Eksekutif

ME1.6 - Tindakan Korektif (C)

b) subdomain ME2

ME2.1 - Pemantauan kerangka kerja pengendalian internal (R, A)

ME2.2 - Tinjauan Pemantauan (R, A)

ME2.3 - Kontrol pengecualian ( $R, A)$

ME2.4 - Kontrol penilaian diri $(\mathrm{R}, \mathrm{C})$

ME2.5 - Pengendalian internal (R, A, C)

ME2.6 - Pengendalian internal pihak ketiga $(\mathrm{R}, \mathrm{C})$

ME2.7 - tindakan korektif (R, A, C, I)

c) subdomain ME3

ME3.1 - Pengungkapan persyaratan kepatuhan hukum, peraturan atau kontrak

Eksternal (R, A, C)

ME3.2 - Optimalisasi Respon Eksternal (R, C)

ME3.3 - Penilaian kepatuhan eksternal (R, A, C)

ME3.4 - Memastikan kepatuhan positif (R, A, C, I)

ME3.5 - Laporan Terintegrasi (R, C, I)

d) subdomain ME4

ME4.1 - Membuat kerangka kerja manajemen TI $(\mathrm{R}, \mathrm{C})$

ME4.2 - Penyelarasan Strategis (R, C) 
ME4.3 - Biaya Pengiriman (R, A, C, I)

ME4.4 - Manajemen Sumber Daya (R, A, C, I)

ME4.5 - Manajemen Risiko (R, C)

ME4.6 - Pengukuran kinerja (R, C, I)

ME4.7 - Garansi Independen (R, C)

\subsection{Tingkat kedewasaan}

Setelah dilakukan analysis data jawaban kuesioner, diperoleh hasil sebagai berikut

Tabel 2. Tingkat Kematangan

\begin{tabular}{ccc}
\hline Nama subdomain & Rata-rata & pembulatan \\
\hline ME1 & 3.00 & 3 \\
SAYA 2 & 2.97 & 3 \\
ME3 & 2.99 & 3 \\
ME4 & 2.93 & 3 \\
\hline
\end{tabular}

\subsection{Analysis Kesenjangan (GAP)}

Setelah nilai maturitas diketahui, gap dianalysis berdasarkan nilai maturitas System Informasi Absensi PT Multi Engineering Perkasa pada nilai target.

Tabel 3. Analysis kesenjangan

\begin{tabular}{cccc}
\hline Nama subdomain & Rata-rata & Target & kesenjangan \\
\hline ME1 & 3.00 & 4 & 1 \\
SAYA 2 & 2.97 & 4 & 1.03 \\
ME3 & 2.99 & 4 & 1.01 \\
ME4 & 2.93 & 4 & 1.07 \\
\hline
\end{tabular}

Sumber Data survei, 2021

Berdasarkan hasil penghitungan ulang nilai aperture dengan ME band di atas, berikut adalah representasi dari grafik radar, sebagai berikut

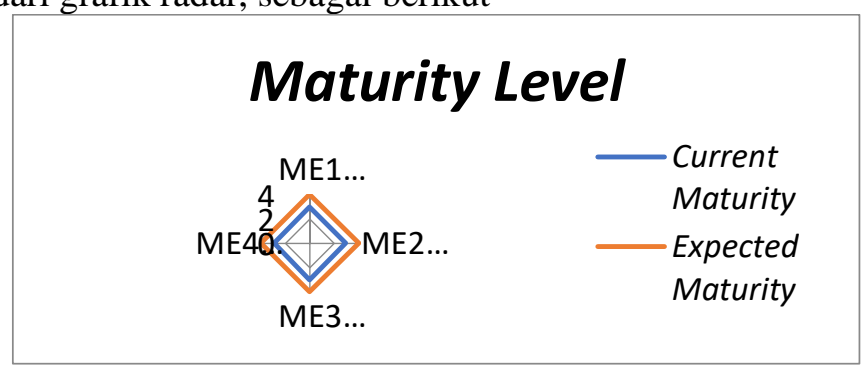

Sumber Data survei, 2021

\subsection{Rekomendasi ME1}

Gambar 2. Bagan tingkat kematangan radar

Berikut saran yangdapat penulis berikan

a) Untuk memantau kinerja TI, PT Multi Engineering Perkasa perlu lebih memperhatikan kebutuhan absensi pengguna system informasi. monitoring perkembangan program system dilakukan analisa serta pengecekan aset bulanan untuk dapat menghasilkan pelayanan yangoptimal.

b) PT Multi Engineering Perkasa juga harus menilai meningkatkan kelayakan system, risiko infrastruktur teknologi yangterkait dengan system informasi absensi yangdigunakan agar kondisi manajemen TI dapat terus mendukung bisnis perusahaan secara optimal.

\subsection{ME2 menawarkan}

Berikut saran yangdapat penulis berikan

a) PT Multi Engineering Perkasa perlu lebih meningkatkan lagi proses absensi IT terkait absensi.

b) PT Multi Engineering Perkasa juga harus menyediakan pemeliharaan system yangmencakup keamanan system, integritas data, dan integrasi system untuk mengurangi masalah ketika pengguna menggunakan system informasi kehadiran. 


\subsection{ME3 menawarkan}

Berikut saran yangdapat penulis berikan

a) PT Multi Engineering Perkasa sebaiknya melakukan penilaian terhadap terms of control atas undang-undang, regulasi, dan kontrak manajemen TI untuk meminimalkan masalah yangdapat mengganggu operasional perusahaan.

b) PT Multi Engineering Perkasa juga harus mengambil tindakan korektif jika ditemukan kesalahan dalam hasil evaluasi TI yangtidak sesuai dengan undangundang, peraturan, atau kontrak perusahaan.

\subsection{ME4 menawarkan}

Berikut saran yangdapat penulis berikan

a) PT Multi Engineering Perkasa sebaiknya menilai keadaan manajemen TI khususnya dalam hal system informasi absensi, untuk meminimalkan masalah yangdapat mengganggu operasional perusahaan.

b) Manajemen PT Multi Engineering Perkasa juga harus meningkatkan koordinasi dan kerjasama dengan staf IT dalam penyediaan layanan system IT yangsesuai dengan kebutuhan operasional perusahaan.

Perhitungan Tingkat Maturity PT Multi Engineering Perkasa adalah total nilai yangdiperoleh pada domain ME pada saat audit awal. Sedangkan untuk kolom selanjutnya, tingkat kematangan berdasarkan penilaian narasumber dari pembimbing, pengamatan penulis terhadap proses wawancara, sehingga hasil akhirnya merupakan analysis oleh penulis, disertai saran saran. Kesamaan antara penelitian saat ini dilakukan[2] [6] [7] [8] [9] [10] \& [11]adalah audit system informasi melalui COBIT Framework. Namun yangmembedakan antara penelitian sebelumnya adalah objek dan waktu penelitian.Menurut penelitian penulis, 7 (tujuh) penelitian sebelumnya yanglebih baik adalah penelitian [2] \& [8] karena mendukung penelitian penulis.

\section{Kesimpulan}

System Informasi Kehadiran diaudit di bawah COBIT 4.1, dengan fokus pada semua subsektor domain ME. Penelitian diperlukan karena PT Multi Engineering Perkasa memiliki masalah absensi, dan perusahaan belum pernah mengaudit system informasi kehadiran. Berdasarkan hasil analysis informasi tingkat kematangan system informasi, dengan menggunakan proses-proses yangterdapat pada subsektor ME1 yangmemiliki nilai pembulatan sampai dengan 3, subsektor ME2 yangmemiliki nilai bulat. 3, subsistem ME3 dengan nilai yangdibulatkan menjadi 3, dan subsistem ME4 yangmemiliki 3 nilai yangdibulatkan. Kematangan TI level 3,

\section{Daftar Pustaka}

[1]. Tukino, "Merancang System Informasi Manajemen Proyek Internet untuk Mengakses Dokumen Koleksi PCBA PT Surya Teknologi Batam," Jurnal Nasional Teknologi dan System Informasi, vol. 2, no 3, hlm. 67-84, 2016, doi https//doi.org/10.25077/TEKNOSI.v2i3.2016.67-84.

[2]. T. Tukino, "System Pendukung Aplikasi Pegadaian Terintegrasi Online Menggunakan Metode Kerangka Kerja COBIT", ijcs, vol. 10, no 1, 2021

[3]. T. Tukino \& A. Amrizal, "Merancang System Informasi Pelaporan Transaksi Online dengan Bahasa Pemrograman PHP dan MySQL Menggunakan PT Pos Indonesia (Persero) Batam 29400”, Jurnal Nasional Teknologi dan System Informasi, vol. 3, no 1, pp. 199-210, 2017, doi https//dx.doi.org/10.25077/TEKNOSI.v3i1.2017.199-210.

[4]. EN Jannah \& AZ Arifin, "System Informasi Absensi Haul Berbasis Web di Pondok Pesantren Muhyiddin Surabaya", Jurnal Ilmiah Teknologi System Informasi, vol. 1, no 1, hlm. 47-59, 2019.

[5]. R. Kurniawan, A. Yohanes, A. Wijaya, Fernaldy, William, \& JF Andry, "Audit Aplikasi Medico Menggunakan COBIT 4.1 Domain ME Framework", Jurnal TEKNOINFO, vol. 12, no 2, hlm. 38-42, 2018. 
[6]. BIAYA 13, no 2, hlm. 97-101, 2018.

[7]. R. Anderson, Kevin \& JF Andry, "Audit Aplikasi Inventaris Menggunakan Framework Cobit 4.1 pada Nonna Store", Jurnal Penelitian dan Pengembangan, vol. 3, no 1, hal. 1-12, 2018.

[8]. T. Tokino, "Analysis Manajemen TI SIPKD Pada Kantor Pemerintah Kota Tanung Pinang Dengan Pendekatan Kerangka Kerja COBIT", JKT, Vol. 4, bukan 1, hal. 10-20 Mei 2018.

[9]. FP Sihotang, "Menilai Tingkat Kematangan Manajemen Teknologi Informasi Menggunakan COBIT 4.1 PT XYZ", Jurnal RESTI (Teknik System dan Teknologi Informasi), 2 (1), hlm. 375-383, 2018.

[10]. Ibrahim \& L. Nurpulaela, "Penilaian Manajemen TI Sangat Baik untuk Mendukung Fungsi TI Berdasarkan COBIT 4.1 PT Timah Tbk. Int", Conf. on Information Tech., Computer, and Electronic Engineering (ICITACEE), hlm. 336-339, 2018

[11]. MDS Asyari \& YS Triana, "Penerapan Toolkit Analysis Kredit Melalui COBIT 4.1", Pendekatan Metode. Jurnal Internasional Ilmu Komputer dan Komputasi Bergerak, vol. 7, no 4, hlm. 153-165, 2018.

[12]. RCS Hariyono, "Audit System Informasi Menggunakan Framework Cobit 4.1 Pada Website Universitas Peradaban", Jurnal SMART COMP, vol. 7, no 1, hlm. 234-239, 2018.

[13]. Noorhasanah, Winarno, W. Wahyu \& D. Adhipta "Penilaian Manajemen Teknologi Informasi Berbasis COBIT 5 Framework", Seminar Nasional IT Multimedia. Yogyakarta 6 - 8 Februari 2019

[14]. Utomo, A. Prasetyo \& M. Novita, «Analysis Teknologi Informasi (It Governance) Bidang Akademik dengan Cobit Frame Work Studi Kasus di Universitas Stikubank Semarang», Jurnal Teknologi Informasi DINAMIK, vol. 16, No. 2, 2016 Juli. Halaman 139149. ISSN $08549524,2016$.

[15]. T. Christiana, "Analysis Manajemen Teknologi Informasi Menggunakan Metode Cobit 4.1 (Studi Kasus PUSDIKLAT Kemenkes RI)", Jurnal Techno Nusa Mandiri vol. XIII, No. 2, September 2016

[16]. EP Rahmi"Pengukuran tingkat kapasitas pengelolaan TI melalui framework COBIT 4.1 (PT. Studi Kasus PT. PDA Net Kota Cirebon) », Journal of CoreIT, Vol.2, No.1, Juni 2016

[17]. AT Namira "Evaluasi Manajemen Teknologi Informasi Dalam System Pendidikan Jarak Jauh Menggunakan Framework COBIT 4.1 (Studi Kasus Sekolah Tinggi Ilmu Kepolisian-Perguruan Tinggi Ilmu Kepolisian)", Jurnal System Informasi dan Informatika (JIFoSI) Vol. 1, No. 1. Maret 2020. 